\title{
Аналіз сучасних шкал для оцінки рівня активності та участі осіб з хребтово-спинномозковою травмою
}

\author{
УдК 796:616.711-616-071-615.825
}

\section{А. В. Терещенко, С. В. Гаврелюк}

Національний університет фізичного виховання і спорту України, Київ, Україна

Резюме. Мета. Проведення аналізу і порівняння тестувань для визначення рівня активності та участі осіб з хребтово-спинномозковою травмою. Методи. Аналіз даних електронних наукових джерел Національної бібліотеки медицини США (PubMed), порівняння та узагальнення. Результати. Для аналізу було обрано три тестування, які, за даними літератури, найчастіше використовуються для оцінювання рівня активності та участі осіб з хребтово-спинномозковою травмою: WHODAS II, SCIM та QIF. Було сформовано порівняльну таблицю характеристик обраних шкал. Висновки. Всі обрані тестування можна використовувати для обстеження рівня активності та участі, валідність кожного з них було доведено відповідними дослідженнями. Жоден із обраних інструментів оцінки не $€$ перекладеним на українську мову та адаптованим до соціально-культурних умов нашої країни. Ключові слова: ерготерапія, обстеження, активність, участь, хребтово-спинномозкова травма.

\section{Анализ современных шкал для оценки уровня активности и участия лиц с позвоночно-спинномозговой травмой}

\section{А. В. Терещенко, С. В. Гаврелюк}

Национальный университет физического воспитания и спорта Украины, Киев, Украина

Резюме. Цель. Проведение анализа и сравнения тестов для определения уровня активности и участия лиц с позвоночно-спинномозговой травмой. Методы. Анализ данных электронных научных источников Национальной библиотеки медицины США (PubMed), сравнение и обобщение. Результаты. Для анализа были выбраны три тестирования, которые, по данным литературы, наиболее часто используются для оценки уровня активности и участия лиц с позвоночно-спинномозговой травмой: WHODAS II, SCIM и QIF. Была сформирована сравнительная таблица характеристик избранных шкал. Выводы. Все выбранные тестирования могут использоваться для обследования уровня активности и участия, валидность каждого из них была доказана соответствующими исследованиями. Ни один из избранных инструментов оценки не переведен на украинский язык и не адаптирован к социально-культурным условиям нашей страны.

Ключевые слова: эрготерапия, обследование, активность, участие, позвоночноспинномозговая травма.

\section{Analysis of modern scales for assessing the level of activity and participation of} persons with vertebral and spinal trauma

\section{A. V. Tereshchenko, S. V. Havreliuk}

National University of Physical Education and Sport of Ukraine, Kyiv, Ukraine

\begin{abstract}
Aim. To conduct analysis and comparison of tests to determine the level of activity and participation of persons with vertebral and spinal trauma. Methods. Analysis of data from electronic scientific sources of the US National Library of Medicine (PubMed), comparisons and generalizations. Results. Three tests were selected for analysis, which, according to the literature, are most often used to assess the level of activity and participation in vertebral and spinal trauma patients: WHODAS II, SCIM and QIF. A comparative table of characteristics of selected scales was formed. Conclusions. All selected tests can be used to examine the level of activity and participation, the validity of each of them has been proved by appropriate studies. None of the selected assessment tools is translated into Ukrainian and adapted to the socio-cultural conditions of our country.

Keywords: ergotherapy, examination, activity, participation, vertebral and spinal trauma.
\end{abstract}


Постановка проблеми. Щорічно в розвинених країнах від 10 до 50 осіб на 1 млн населення отримують хребтово-спинномозкову травму (ХСМT) [14]. Понад 50 \% всіх травм трапляються в осіб віком 16-30 років [8]. Близько $80 \%$ всіх осіб з ХСМТ є чоловіками [14]. Автомобільні аварії $\epsilon$ найчастішою причиною гострих травм $44 \%[11,14]$. Очікувану тривалість життя осіб, які отримали травму у 20-річному віці, було розраховано таким чином: 33 роки - для осіб з високою тетраплегією, 39 років - з низькою тетраплегією і 44 роки - з параплегією [14].

Пошкодження вище від конуса спинного мозку $\epsilon$ ураженнями верхнього мотонейрона $\mathrm{i}$ проявляються частковою або повною втратою довільних рухів, підвищенням м'язового тонусу, підвищенням сухожилкових рефрлексів, появою патологічних рефлексів. Пошкодження нижче від конуса спинного мозку $є$ ураженнями нижнього мотонейрона і проявляються частковою або повною втратою довільних рухів, зниженням м'язового тонусу, втратою сухожилкових рефрлексів, м'язовою атрофрією нижче від рівня травми [12].

У грудні 2017 р. в Україні було впроваджено план щодо імплементації Міжнародної класифікації функціонування, обмежень життєдіяльності та здоров'я (МКФ), яка є підгрунтям для розвитку системи реабілітації в нашій країні. Класифікація містить кілька компонентів: функції і структура тіла, активність та участь, контекстуальні чинники. Саме зі складовими активності та участі працює новий для сфери фрізичної та реабілітаційної медицини України фахівець - ерготерапевт.

Обстеження $\epsilon$ однією $з$ найважливіших складових надання реабілітаційних послуг, результати якого визначають втручання і яке має безпосередній влив на його ефективність [21]. Сучасний український ерготерапевт повинен володіти спеціалізованими, стандартизованими інструментами оцінки для імплементації МКФ в нашій країні. Проте на сьогодні серед українських наукових праць не було знайдено обстежень компонентів активності та участі.

Мета дослідження - провести аналіз і порівняння варіантів тестувань активності та участі осіб з хребтово-спинномозковою травмою.

Результати дослідження та їх обговорення. Визначити прогноз хребтово-спинномозкової травми можна за результатами обстеження відповідно до Шкали пошкодження Американської асоціації спінальної травми (American Spinal Injury Association (ASIA) Impairment Scale (AIS)). Класифрікація базується на стандартизованому обстеженні моторної та сенсорної функцій. Це необхідно для визначення двох сенсорних, двох моторних і неврологічного рівнів ураження [12, 17, 22].

Моторну фрункцію досліджують шляхом тестування функцій ключових м'язів на десяти міотомах верхніх і нижніх кінцівок кожної половини тіла. Сенсорну фрункцію визначають тестуванням ключових сенсорних точок у 28 дерматомах кожної половини тіла $[12,16]$.

Також за допомогою AIS хребтово-спинномозкові травми класифікують на повні (AIS A) та неповні (AIS B, C, D, E). Різниця між повним та неповним ураженням базується на наявності/ відсутності моторної та/або сенсорної функції в сегментах $\mathrm{S}_{4}-\mathrm{S}_{5}$ та сили в м'язах нижче від моторного і неврологічного рівнів травми $[12,17]$. Неврологічний рівень уражень - найбільш каудальний сегмент спинного мозку з нормальною сенсорною функцією і збереженою моторною функцією (3 бали і вище за мануально-м'язовим тестом) [21].

Найважливішою детермінантою прогнозу є те, чи травма $є$ клінічно повною або неповною [5]. Більша частина відновних процесів відбувається протягом перших двох місяців після ураження, хоча відновлення може тривати до одного року, а іноді навіть більше ніж рік [12]. В осіб з повним ураженням спинного мозку (AIS A) можливість клінічно значущого неврологічного відновлення $\epsilon$ низькою [12].

Для аналізу тестувань активності та участі осіб з ХСМТ було обрано три шкали, які, за даними літератури, найчастіше використовуються: Оцінка інвалідності Всесвітньої організації охорони здоров'я II (World Health Organization Disability Assessment Schedule II (WHODAS II)), Ступінь незалежності для осіб з ураженням спинного мозку (Spinal Cord Independence Measure (SCIM)) та Показник функціональності осіб з тетраплегією (Quadriplegia Index of Function (QIF)). У результаті аналізу літературних джерел було сформовано порівняльну таблицю тестувань (табл. 1).

Тестування WHODAS II було розроблено й опубліковано Всесвітньою організацією охорони здоров'я в 2010 р. Це інструмент, що вимірює повсякденне функціонування в 6 категоріях (розуміння і комунікація, мобільність, самообслуговування, налагодження зв'язків з оточуючими людьми, активності повсякденного життя, участь у житті суспільства), які відповідають компонентам активності та участі за МКФ [18]. Його було розроблено як загальний метод обстеження, придатний для використання при різних станах здоров'я, в різних країнах та культурах [1]. Тестування було перекладено на 47 мов та діалек- 
ТАБЛИЦЯ 1 - Порівняльна характеристика тестувань активності та участі

\begin{tabular}{|c|c|c|c|}
\hline $\begin{array}{c}\text { Назва обстеження/ } \\
\text { характеристика }\end{array}$ & WHODAS II & SCIM & QIF \\
\hline $\begin{array}{l}\text { Діагноз/стан здоров'я } \\
\text { пацієнта }\end{array}$ & $\begin{array}{l}\text { Артрит } \\
\text { Іेнсульт } \\
\text { Хребтово-спинномозкова травма } \\
\text { Іेнші нозологічні групи }\end{array}$ & Хребтово-спинномозкова травма & $\begin{array}{l}\text { Хребтово-спинномозкова } \\
\text { травма }\end{array}$ \\
\hline Вік пацієнта & $\begin{array}{l}13-17 \text { років } \\
18-64 \text { роки }\end{array}$ & $\begin{array}{l}13-17 \text { років } \\
18-64 \text { роки } \\
65+\end{array}$ & $\begin{array}{l}18-64 \text { роки } \\
65+\end{array}$ \\
\hline Тип обстеження & Самооцінка пацієнтом & $\begin{array}{l}\text { Самооцінка пацієнтом } \\
\text { Спостереження }\end{array}$ & Спостереження \\
\hline $\begin{array}{l}\text { Необхідні предмети для } \\
\text { проведення обстеження }\end{array}$ & $\begin{array}{l}\text { Листок із тестом } \\
\text { Ручка }\end{array}$ & $\begin{array}{l}\text { Листок із тестом } \\
\text { Ручка }\end{array}$ & $\begin{array}{l}\text { Листок із тестом } \\
\text { Ручка }\end{array}$ \\
\hline $\begin{array}{l}\text { Час, необхідний для } \\
\text { проведення тестування }\end{array}$ & До 20 хв & $\begin{array}{l}\text { До } 60 \text { хв ( } 30-45 \text { хв - спостере- } \\
\text { ження; 10-15 хв - інтерв'ю) }\end{array}$ & До 30 хв \\
\hline $\begin{array}{l}\text { Необхідна підготовка } \\
\text { екзаменатора }\end{array}$ & Необхідно прочитати інструкцію & Необхідно прочитати інструкцію & $\begin{array}{l}\text { Спеціальна підготовка не } \\
\text { потрібна }\end{array}$ \\
\hline Компонент МКФ & $\begin{array}{l}\text { Активність } \\
\text { Участь }\end{array}$ & Активність & $\begin{array}{l}\text { Активність } \\
\text { Участь }\end{array}$ \\
\hline Складові тестування & $\begin{array}{l}\text { Шість категорій: } \\
\text { 1. Розуміння і комунікація. } \\
\text { 2. Мобільність. } \\
\text { 3. Самообслуговування. } \\
\text { 4. Налагодження зв'язків з оточу- } \\
\text { ючими людьми. } \\
\text { 5. Життєві активності. } \\
\text { 6. Участь у житті суспільства }\end{array}$ & $\begin{array}{l}\text { Три категорії: } \\
\text { 1. Самообслуговування. } \\
\text { 2. Менеджмент дихання та роботи } \\
\text { сфінктерів. } \\
\text { 3. Мобільність }\end{array}$ & $\begin{array}{l}\text { Десять категорій: } \\
\text { 1. Трансфери. } \\
\text { 2. Догляд за волоссям та } \\
\text { обличчям. } \\
\text { 3. Прийом ванни/душу. } \\
\text { 4. Одягання. } \\
\text { 5. Прийом їжі. } \\
\text { 6. Мобільність. } \\
\text { 7. Мобільність у ліжку. } \\
\text { 8. Програма догляду } \\
\text { за діяльністю сечового } \\
\text { міхура. } \\
\text { 9. Програма догляду за } \\
\text { діяльністю кишечнику. } \\
\text { 10. Розуміння особистого } \\
\text { догляду }\end{array}$ \\
\hline Оцінка & $\begin{array}{l}\text { Максимальна кількість балів - } \\
100 . \\
\text { Оцінки варіюють від } 0 \text { до } 4 \text { балів: } \\
0 \text { балів - без труднощів; } \\
1 \text { бал - незначні труднощі; } \\
2 \text { бали - помірні труднощі; } \\
3 \text { бали - значні труднощі; } \\
4 \text { бали - надзвичайні труднощі } \\
\text { або виконати неможливо }\end{array}$ & $\begin{array}{l}\text { Максимальна кількість балів - } 100 . \\
\text { Сума балів субшкали «Самообслу- } \\
\text { говування» - } 20 . \\
\text { Сума балів субшкали «Менедж- } \\
\text { мент дихання та роботи сфінк- } \\
\text { терів» - } 40 . \\
\text { Сума балів субшкали «Мобіль- } \\
\text { ність»- } 40\end{array}$ & $\begin{array}{l}\text { Максимальна кількість } \\
\text { балів - } 100 . \\
\text { Кожне моторне завдання } \\
\text { оцінюється від } 0 \text { до } 4 \text { балів } \\
\text { залежно від збільшення } \\
\text { самостійності }\end{array}$ \\
\hline
\end{tabular}

тів [7]. Офріційного перекладу на українську мову немає.

Валідність і надійність тестування WHODAS II для осіб з ХСМТ було доведено в дослідженні Wolf AC у 2012 р. [23]. Порівняно з іншими валідованими оцінками участі для осіб з ХСМТ перевагами цього тестування $€$ те, що жодне інше обстеження не має такого поділу на субшкали, який безпосередньо узгоджується з компонентами МКФ [23]. Проте WHODAS II не оцінює таких специфічних для осіб з ХСМТ станів, як менеджмент дихання, сечового міхура та кишечнику.

SCIM дає змогу дослідити здатність людини з ХСМТ виконувати активності повсякденного жит- тя. Це тестування складається з 19 завдань, які об'єднано в три субшкали: самообслуговування; менеджмент дихання, сечового міхура та кишечнику; мобільність. SCIM оцінює основні активності повсякденного життя, такі як вживання їжі, догляд за волоссям та обличчям, прийом ванни чи душу, одягання. Мобільність визначають як у кімнаті та туалеті, так і за межами приміщення $[6,15]$. Тест $є$ безкоштовним, для його проведення потрібні лише листок із тестом і ручка.

Валідність SCIM було підтверджено у ході спостереження за 425 суб'єктами з 13 центрів у 6 країнах, так само як і надійність тесту [6]. SCIM схвалена міжнародною спільнотою ХСМТ як най- 
доцільніше обстеження ступеня незалежності осіб з XCMT. SCIM вірогідно відображає те, що більшість клініцистів і людей з ХСМТ очікують побачити під час обстеження активностей повсякденного життя та незалежності $[3,4,13,19]$.

Остання версія SCIM (SCIM III) була рекомендована міжнародними дослідженнями як ключовий інструмент оцінки осіб з ХСМТ як у клінічному середовищі, так і в науковому $[2,3$, 9]. Тестування було перекладено та адаптовано до використання приблизно в десяти країнах, зокрема, Італії, Іспанії, Великій Британії, Бразилії, Туреччині [20]. Офіційного перекладу на українську мову немає.

Тестування QIF було спеціально розроблено для обстеження осіб з тетраплегією. Мета полягала у розробці чутливої шкали для вимірювання функціональних завдань під час реабілітації в цій підгрупі осіб з ХСМТ, оскільки наявні інструменти вважалися нечутливими до виявлення незначних, але важливих фрункціональних покращень в активностях повсякденного життя у людей 3 травмами шийного відділу хребта [10].

QIF обстежує рівень незалежності в десяти категоріях активностей повсякденного життя: трансфери, догляд за волоссям та обличчям, прийом ванни /душу, одягання, вживання їжі, мобільність, мобільність у ліжку, програма догляду за діяльністю сечового міхура, програма догляду

\section{Література}

1. Abedzadeh-Kalahroudi M. Psychometric properties of the world health organization disability assessment schedule II-12 Item (WHODAS II) in trauma patients / M. Abedzadeh-Kalahroudi, E. Razi, M. Sehat, M. AsadiLari // Injury. - 2016 May. - Vol. 47(5). - P. 1104-1108.

2. Alexander M. S. Outcome measures in spinal cord injury: recent assessments and recommendations for future directions / M. S. Alexander, K. D. Anderson, F. Biering-Sorensen, A. R Blight, R. Brannon, T. N. Bryce et al. // Spinal Cord. - 2009 Aug. - Vol. 47(8). - P. 582-591.

3. Anderson $K$. Functional recovery measures for spinal cord injury: an evidence-based review for clinical practice and research / K. Anderson, S. Aito, M. Atkins, F. Biering-Sorensen, S. Charlifue, A. Curt et al. // The j. of spinal cord medicine. - 2008. - N 31(2). - P. 133-144.

4. Bluvshtein V. SCIM III is reliable and valid in a separate analysis for traumatic spinal cord lesions / V. Bluvshtein, L. Front, M. Itzkovich, E. Aidinoff, I. Gelernter, J. Hart et al. // Spinal Cord. - 2011 Feb. - Vol. 49(2). - P. 292-296.

5. Burns A. S. Clinical diagnosis and prognosis following spinal cord injury / A. S. Burns, R. J. Marino, A. E. Flanders, H. Flett // Handb. Clin. Neurol. - 2012. - N 109. - P. 47-62.

6. Catz A. L. A multicenter international study on the Spinal Cord Independence Measure, version III: Rasch psychometric validation I A. L. Catz, M. Itzkovich, L. Tesio, F. Biering-Sorensen, C. Weeks, M. T. Laramee, et al. // Spinal Cord. - 2007 Apr. - Vol. 45(4). - P. 275-291.

7. Federici S. World Health Organization Disability Assessment Schedule 2.0: An International Systematic Review/S. Federici, M. Bracalenti, F. Meloni, J. V. Luciano // Disability and Rehabilitation. - 2016. - Vol. 39(23). - P. 2347-2380 за діяльністю кишечнику, розуміння особистого догляду. QIF не оцінює здатність ходити рівними поверхнями та сходами, менеджмент дихання та сечового міхура $[3,19]$. Дані щодо наявності перекладів тестування на інші мови не було знайдено.

Існує лише три порівняльні дослідження валідності тесту, які було проведено на 20 суб'єктах 3 повною тетраплегією, та одне дослідження надійності $[3,10]$. QIF видається корисним тестом для осіб з травмою шийного відділу хребта для моніторингу функціонального прогресу, оцінювання ефрективності реабілітації в пацієнтів неврологічного профрілю і як критерій оцінки в клінічних випробуваннях. QIF рекомендують продовжувати розробляти та підтверджувати для використання як додатковий інструмент для осіб з ураженням шийного відділу хребта [3].

Висновки. Внаслідок проведеного дослідження 3'ясувалося, що хоча в проаналізованих тестуваннях дещо різняться зміст та складові тестів і методика оцінки результатів, кожне з них не потребує спеціального обладнання чи складної підготовки екзаменатора та може використовуватися для дорослих осіб з хребтово-спинномозковою травмою. Валідність і надійність кожного обстеження було доведено відповідними дослідженням, але жодне тестування не $\epsilon$ перекладеним на українську мову.

\section{References}

1. Abedzadeh-Kalahroudi, M., Razi, E., Sehat, M., Asadi-Lari, M. (2016 May). Psychometric properties of the world health organization disability assessment schedule II-12 Item (WHODAS II) in trauma patients. Injury, 47(5), 1104-1108.

2. Alexander, M.S., Anderson, K.D., Biering-Sorensen, F., Blight, A.R., Brannon, R., Bryce, T.N., et al. (2009 Aug). Outcome measures in spinal cord injury: recent assessments and recommendations for future directions. Spinal Cord, 47(8), 582-591.

3. Anderson, K., Aito, S., Atkins, M., Biering-Sorensen, F., Charlifue, S., Curt, A., et al. (2008). Functional recovery measures for spinal cord injury: an evidence-based review for clinical practice and research. The journal of spinal cord medicine, 31(2), 133-144.

4. Bluvshtein, V., Front, L., Itzkovich, M., Aidinoff, E., Gelernter, I., Hart, J., et al. (2011 Feb). SCIM III is reliable and valid in a separate analysis for traumatic spinal cord lesions. Spinal Cord, 49(2), 292-296.

5. Burns, A.S., Marino, R.J., Flanders, A.E., Flett, H. (2012). Clinical diagnosis and prognosis following spinal cord injury. Handb. Clin. Neurol., 109, 47-62

6. Catz, A.L., Itzkovich, M., Tesio, L., Biering-Sorensen, F., Weeks, C., Laramee, M.T., et al. (2007 Apr). A multicenter international study on the Spinal Cord Independence Measure, version III: Rasch psychometric validation. Spinal Cord, 45(4), 275-291.

7. Federici, S., Bracalenti, M., Meloni, F., Luciano, J.V. (2016). World Health Organization Disability Assessment Schedule 2.0: An International Systematic Review. Disability and Rehabilitation, 39(23), 2347-2380.

8. Fehlings, M.G., Vaccaro, A.R., Boakye, M. (2012). Essentials of Spinal Cord Injury: Basic Research to Clinical Practice. Thieme, $682 \mathrm{p}$. 
8. Fehlings M. G. Essentials of Spinal Cord Injury: Basic Research to Clinical Practice / M. G. Fehlings, A. R. Vaccaro, M. Boakye. - Thieme, 2012. $-682 p$.

9. Furlan J. Assessment of disability in patients with acute traumatic spinal cord injury: a systematic review of the literature / J. Furlan, V. Noonan, A. Singh, M. Fehlings // J. Neurotrauma. - 2011. - Vol. 28. - P. 1413-1430.

10. Gresham G. E. The Quadriplegia Index of Function (QIF): sensitivity and reliability demonstrated in a study of thirty quadriplegic patients / G. E. Gresham, M. L. Labi, S. S. Dittmar, J. T. Hicks, S. Z. Joyce, M. A. Stehlik // Paraplegia. - 1986 Feb. - N 24(1). - P. 38-44.

11. Hagen E. M. Traumatic spinal cord injuries - incidence, mechanisms and course / E. M. Hagen, T. Rekand, N. E. Gilhus, M. Gronning // Tidsskr Nor Legeforen. - 2012. - N 132. - 831 p.

12. Harvey L. A. Management of Spinal Cord Injuries: A Guide for Physiotherapists / L. A. Harvey. - Elsevier Health Sciences, 2008. - 297 p.

13. Harvey L. A. The spinal cord independence measure / L. A. Harvey, K. D. Anderson // J. of Physiotherapy. - 2015 Apr. - N 61(2). - P. 99.

14. Holtz A. Spinal Cord Injury / A. Holtz, R. Levi. - Oxford University Press, 2010. $-336 \mathrm{p}$.

15. Itzkovich M. The Spinal Cord Independence Measure (SCIM) version III: reliability and validity in a multi-center international study I M. Itzkovich, I. Gelernter, F. Biering-Sorensen, C. Weeks, M. T. Laramee, B. C. Craven, et al. // Disability and Rehabilitation. - 2007 Dec 30. - Vol. 29(24). - P. 1926-1933.

16. Kirshblum S. C. International Standards for Neurological Classification of Spinal Cord Injury: Cases with classification challenges / S. C. Kirshblum, F. Biering-Sorensen, R. Betz, S. Burns, W. Donovan, D. E. Graves et al. // J. of Rehabilitation Medicine. - 2014 March. - N 37(2). - P. 120-127.

17. Kirshblum S. C. International standards for neurological classification of spinal cord injury (Revised 2011) / S. C. Kirshblum, S. P. Burns, F. Biering-Sorensen, W. Donovan, D. E. Graves, A. Jha // J. Spinal Cord Med. - 2011 Nov. - Vol. 34(6). - P. 535-546.

18. Kuo C. Y. Functioning and disability analysis of patients with traumatic brain injury and spinal cord injury by using the world health organization disability assessment schedule 2.0 / C.Y. Kuo, T.H. Liou, K.H. Chang, W.C. Chi, R. Escorpizo, C. F. Yen // Int. J. Environ. Res. Public Health. - 2015. - Vol. 12(4). - P. 4116-4127.

19. Marino R. J. Domains of outcomes in spinal cord injury for clinical trials to improve neurological function / R. J. Marino // J. of Rehabilitation Research \& Development. - 2007. - N 44(1). - P. 113-122.

20. Nitsch K. P. Measurement Characteristics and Clinical Utility of the Spinal Cord Independence Measure-III Among Individuals With Spinal Cord Injury / K. P. Nitsch, Stipp KL. // Archives of Physical Medicine and Rehabilitation. - 2016. - Vol. 97. - P. 1601-1603.

21. Radomski M. V. Occupational Therapy for Physical Dysfunction / M. V. Radomski, C. A. Trombly. - 7th ed. - LWW; Seventh, North American, 2013. $-1536 p$.

22. Weidner N. Neurological Aspects of Spinal Cord Injury / N. Weidner, R. Rupp, K. E. Tansey. - Springer, 2017. - 770 p.

23. Wolf $A$. C. The World health organization Disability Assessment Schedule II, WHODAS II: reliability and validity in the measurement of activity and participation in a spinal cord injury population / A. C. Wolf, R. L. Tate, N. A. Lannin, J. Middleton, A. Lane-Brown, I. D. Cameron // J. of Rehabilitation Medicine. - 2012. - Vol. 44. - P. 47-755.

\section{Спортивна медицина і фізична реабілітація, №2, 2018}

9. Furlan, J., Noonan, V., Singh, A., Fehlings, M. (2011). Assessment of disability in patients with acute traumatic spinal cord injury: a systematic review of the literature. J. Neurotrauma, 28, 1413-1430.

10. Gresham, G.E., Labi, M.L., Dittmar, S.S., Hicks, J.T., Joyce, S.Z., Stehlik, M.A. (1986 Feb). The Quadriplegia Index of Function (QIF): sensitivity and reliability demonstrated in a study of thirty quadriplegic patients. Paraplegia, 24(1), 38-44.

11. Hagen, E.M., Rekand, T., Gilhus, N.E., Gronning, M. (2012). Traumatic spinal cord injuries - incidence, mechanisms and course. Tidsskr Nor Legeforen, 132, 831.

12. Harvey, L.A. (2008). Management of Spinal Cord Injuries: A Guide for Physiotherapists. Elsevier Health Sciences, $297 \mathrm{p}$.

13. Harvey, L.A., Anderson, K.D. (2015 Apr). The spinal cord independence measure. J. of Physiotherapy, 61(2), 99.

14. Holtz, A., Levi, R. (2010). Spinal Cord Injury. Oxford University Press, $336 \mathrm{p}$.

15. Itzkovich, M., Gelernter, I., Biering-Sorensen, F., Weeks, C., Laramee, M.T., Craven, B.C., et al. (2007 Dec 30). The Spinal Cord Independence Measure (SCIM) version III: reliability and validity in a multicenter international study. Disability and Rehabilitation, 29(24), 1926-1933.

16. Kirshblum, S.C., Biering-Sorensen, F., Betz, R., Burns, S., Donovan, W., Graves, D.E., et al. (2014 March). International Standards for Neurological Classification of Spinal Cord Injury: Cases with classification challenges. J. of Rehabilitation Medicine, 37(2), 120-127.

17. Kirshblum, S.C., Burns, S.P., Biering-Sorensen, F., Donovan, W., Graves, D.E., Jha, A. (2011 Nov). International standards for neurological classification of spinal cord injury (Revised 2011). J. Spinal Cord Med, 34(6), 535-546.

18. Kuo, C.Y., Liou, T.H., Chang, K.H., Chi, W.C., Escorpizo, R., Yen, C.F. (2015). Functioning and disability analysis of patients with traumatic brain injury and spinal cord injury by using the world health organization disability assessment schedule 2.0. Int. J. Environ. Res. Public Health, 12(4), 4116-4127.

19. Marino, R.J. (2007). Domains of outcomes in spinal cord injury for clinical trials to improve neurological function. J. of Rehabilitation Research \& Development, 44(1), 113-122.

20. Nitsch, K.P, Stipp, K.L. (2016). Measurement Characteristics and Clinical Utility of the Spinal Cord Independence Measure-III Among Individuals With Spinal Cord Injury. Archives of Physical Medicine and Rehabilitation, 97, 1601-1603.

21. Radomski, M.V., Trombly, C.A. (2013). Occupational Therapy for Physical Dysfunction. 7th ed. LWW; Seventh, North American, 1536 p.

22. Weidner, N., Rupp, R., Tansey, K.E. (2017). Neurological Aspects of Spinal Cord Injury. Springer, $770 \mathrm{p}$.

23. Wolf, A.C., Tate, R.L., Lannin, N.A., Middleton, J., Lane-Brown, A., Cameron, I.D. (2012). The World health organization Disability Assessment Schedule II, WHODAS II: reliability and validity in the measurement of activity and participation in a spinal cord injury population. J. of Rehabilitation Medicine, 44, 47-755. 